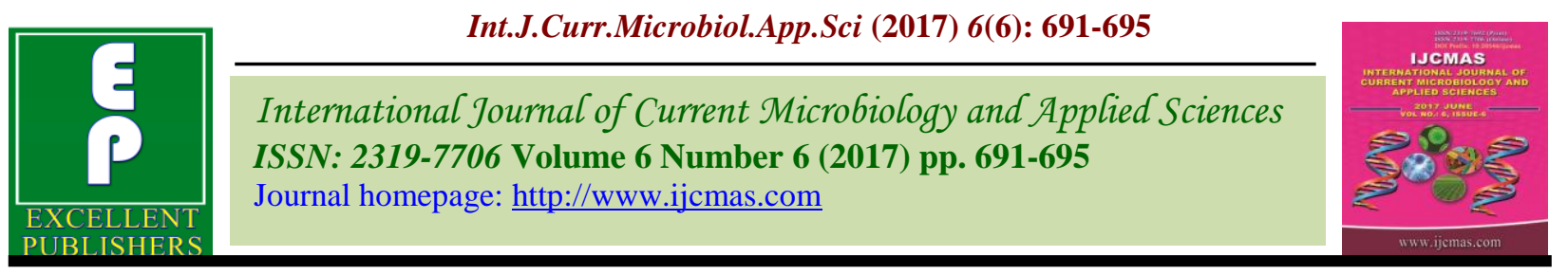

Original Research Article

https://doi.org/10.20546/ijcmas.2017.606.081

\title{
Studies on Seed Priming with Hydrogen Peroxide for Mitigating Salt Stress in Rice
}

\author{
G. Hemalatha ${ }^{1 *}$, J. Renugadevi ${ }^{1}$ and T. Eevera ${ }^{2}$ \\ ${ }^{1}$ Department of Seed Science and Technology, \\ Tamil Nadu Agricultural University, Coimbatore - 641 003, India \\ ${ }^{2}$ Seed Science and Technology, Department of Plant Breeding and Genetics, Anbil \\ Dharmalingam Agricultural College and Research Institute, Trichy - 620 009, India \\ *Corresponding author
}

\begin{tabular}{|c|c|}
\hline & A B S T R A C T \\
\hline $\begin{array}{l}\text { Rice, } \\
\text { Salt stress, } \\
\text { Seed priming, } \\
\mathrm{H}_{2} \mathrm{O}_{2} \text {, } \\
\text { Germination rate. }\end{array}$ & \multirow{3}{*}{$\begin{array}{l}\text { The study to evaluate the effect of seed priming with hydrogen peroxide } \\
\left(\mathrm{H}_{2} \mathrm{O}_{2}\right)(0.25,0.50 \text { and } 0.75 \%) \text { on seed germination and vigour of three } \\
\text { different rice varieties of salt tolerant (TNAU Rice TRY 3), salt sensitive } \\
\text { [ADT (R) 49] and moderately salt tolerant }(\mathrm{Co} 43) \text { varieties at different salt } \\
\text { concentrations }(100,150 \text { and } 200 \mathrm{mM}) \text { revealed that seed priming with } \\
\text { hydrogen peroxide @ } 0.25 \% \text { recorded maximum germination in all the } \\
\text { varieties when compared with hydroprimed and unprimed seeds } \\
\text { irrespective of the salt concentrations. This treatment improved the } \\
\text { germination performance of the salt sensitive rice variety (ADT (R) 49) } \\
\text { also under higher } \mathrm{NaCl} \text { concentrations. }\end{array}$} \\
\hline Article Info & \\
\hline $\begin{array}{l}\text { Accepted: } \\
\text { 14 May } 2017 \\
\text { Available Online: } \\
\text { 10 June } 2017\end{array}$ & \\
\hline
\end{tabular}

\section{Introduction}

Salt stress imposes a major environmental threat to agriculture. Due to varying climatic conditions, the plants had undergone various abiotic stresses. Among these, salt stress has a major constraint in the delta regions. Especially, $\mathrm{NaCl}$ is one of the most abundant and powerful salt which causes nutrient deficiency and also create toxicity to the plant metabolism (Azevedo et al., 2006). In addition to that, when the plants were exposed to the high salinity conditions, there having a capability to produce more Reactive Oxygen Species such as superoxide $\left(\mathrm{O}_{2}{ }^{-}\right)$, hydrogen peroxide $\left(\mathrm{H}_{2} \mathrm{O}_{2}\right)$ and hydroxyl radicals $(\mathrm{OH} \bullet)$ (Implay, 2003). ROS formation leads to changes in intercellular redox homeostasis and it is now widely accepted that redox signals are key regulators of plant metabolism, morphology and development (Bowler and Fluhur, 2000; Foyer and Noctor, 2003). $\mathrm{H}_{2} \mathrm{O}_{2}$ may plays an important role in signal transduction for abiotic stress tolerance, although $\mathrm{H}_{2} \mathrm{O}_{2}$ is toxic at high concentrations (Uchida, 2003). To improve the stress tolerance in plants, controlling the free radicals is the better way (Bor et al., 2003). There is an increased production of hydrogen peroxide leads to improve the survival of the crop plants. 
Among various techniques, seed priming is the effective way to mitigate the effect of stress condition in different plants. Generally, seed priming maintains the uniformity and rate of emergence of the crop (Bakht et al., 2010). The general purpose of priming is to initiate the germination process but not completed due to partial hydration of seeds. Specifically under stress conditions, it induces the germination changes and which is to maintain the germination rate and uniformity in the seedling emergence (Ashraf and Fool and, 2005). Seed priming with $\mathrm{H}_{2} \mathrm{O}_{2}$ having the capacity to enhance the multi-resistance to heat, drought, chilling and salt stress (Uchida et al., 2002).

Keeping this view, a study was conducted to evaluate the effect of seed priming with $\mathrm{H}_{2} \mathrm{O}_{2}$ in the rice seeds of salt tolerant, salt sensitive and moderately salt tolerant varieties under salt stress conditions.

\section{Materials and Methods}

Experiments were carried out at Department of Seed Science and Technology, Tamil Nadu Agricultural University, Coimbatore. The seeds of three different rice varieties of salt tolerant (TNAU Rice TRY 3), salt sensitive (ADT (R) 49) and moderately salt tolerant (Co 43) varieties were taken for the study.

The seedswere primed with $\mathrm{H} 2 \mathrm{O} 2$ at different concentrations of $0.25,0.50$ and $0.75 \%$ in the respective solution for the duration of 12 hours@1:1 ratio of seeds to solution. After that, seeds were removed from the solutions and shade dried at room temperature to bring back its original moisture content for assessing the seed quality parameters.

The germination test was conducted by following procedure outlined in using between paper method in order to assess salt stress effect on seed germination.
Germination paper used for conducting germination test was pre-soaked in various concentration of $\mathrm{NaCl}$ solution viz., 0, 100, 150 and $200 \mathrm{mM}$ concentrations. Four replicates of 100 seeds each were germinated in a seed germinator maintained at $25 \pm 2{ }^{\circ} \mathrm{C}$ temperature and $95 \pm 3 \%$ RH. After fourteenth day, the seedlings were evaluated and the normal seedlings were counted and expressed in percentage (ISTA, 2011).

At the time of germination count in roll towel method, ten normal seedlings were selected at random from each replication and used for measuring the seedling length. The values were calculated and expressed in centimetre.

The seedlings used for growth measurement were placed in a paper cover and dried in shade for $24 \mathrm{~h}$ and then kept in an oven maintained at $85 \pm 2^{\circ} \mathrm{C}$ for $24 \mathrm{~h}$. The dried seedlings were removed from the hot air oven and cooled in the desiccators over silica gel. Dry weight was recorded and the mean values were expressed in $\mathrm{mg} / 10$ seedlings.

\section{Statistical analysis}

The data obtained from each of the experiments were subjected to an analysis of variance and treatment differences tested for significance $(\mathrm{P}=0.05)$. Wherever necessary, the per cent values were transformed to arcsine values before analysis. The critical differences (CD) were calculated at 5 and 1 per cent probability level (Gomez and Gomez, 1984).

\section{Results and Discussion}

Seed germination is the most critical stage in seedling establishment which determines the successful crop production. Pre sowing seed quality enhancement causes early, enhanced germination and growth rate of seedlings. During seed priming, the amount of water 
absorption is controlled so as to allow necessary metabolic activities for germination to take place but prevent radicle emergence by limiting the seed water content, different physiological activities occur within the seed at different moisture level. Salinity is reported to decrease as well as delay the germination of most of the crops. In this present study, seed priming with $\mathrm{H}_{2} \mathrm{O}_{2}(0.25,0.50$ and 0.75 $\%$ ) had been increased the germination over control and hydropriming in all the three rice varieties with varied salt concentrations media including higher salt concentrations (200 $\mathrm{mM}$ ) and results were illustrated in figure 1A. The germination percentage of seeds and salt concentrations were inversely proportional.

The germination percentage was significantly decreased with increased salt concentration in all the three varieties. In salt sensitive variety [ADT (R) 49], seed priming with $0.25 \% \mathrm{H}_{2} \mathrm{O}_{2}$ enhanced the seed germination by $13 \%$ than the unprimed control and $11 \%$ than hydroprimed seeds even at higher salt concentration of $200 \mathrm{mM}$. Similarly, in moderately salt tolerant variety (Co 43), 15\% germination improvement was recorded than the unprimed control and $14 \%$ than hydroprimed seeds. The salt tolerant variety (TNAU Rice TRY 3), recorded $11 \%$ germination improvement than the unprimed control and 9\% improvement than hydroprimed seeds at higher salt concentration of $200 \mathrm{mM}$.

Similar results were found in rice (Uchida et al., 2002) and in wheat (Wahid et al., 2007) both revealed that at lower levels of $\mathrm{H}_{2} \mathrm{O}_{2}$ increases the growth and physiological phenomena by preventing oxidative damage and enhanced the capacity to withstand in high salinity conditions. According to, Azevedo Neto et al., (2005) in maize suggested that $\mathrm{H}_{2} \mathrm{O}_{2}$ induced an increase in salt tolerance during subsequent exposure to salt stress by the incorporation of hydroponics solution. In addition to that Srinieng et al., (2015) revealed that salinity can retard the germination under higher salt concentration in tomato seedling.

Fig.1 The effect of $\mathrm{H}_{2} \mathrm{O}_{2}$ on growth of rice seedlings of primed and unprimed seeds under salt stress conditions. A) Germination percentage (\%), B) seedling length (cm),

C) Dry matter production $\mathrm{g} / 10$ seedlings and D) Vigour index

A

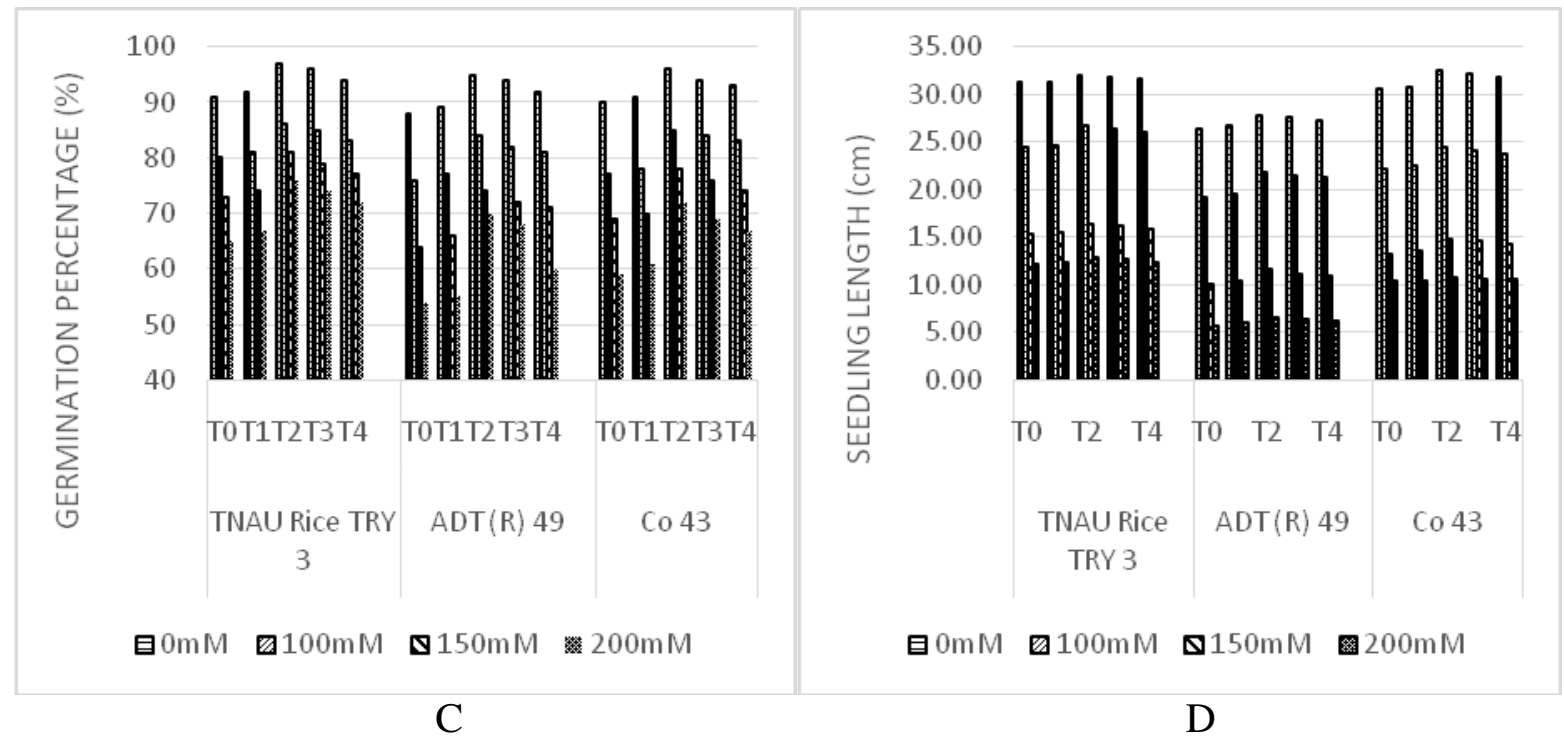




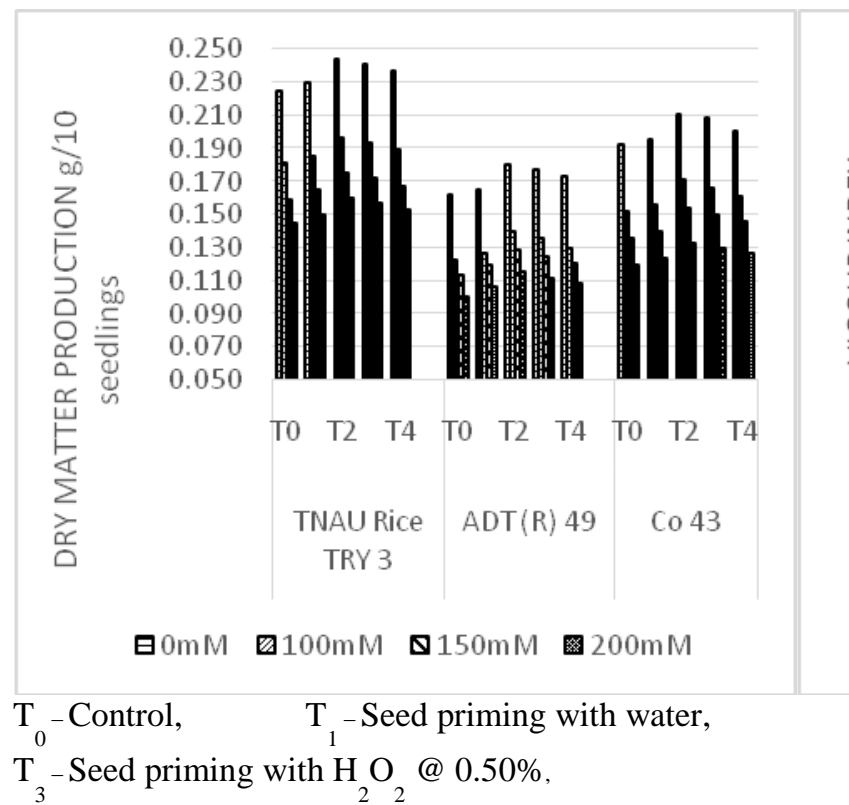

Similarly there was a decreased seedling length with increased salinity condition. The seedling length was observed maximum at lower salinity level and constantly decreased with higher salinity level. According to, Hakim et al., (2010) any crops growing under salinity condition there may be a reduction in seedling length. Similar results were observed in indica rice varieties there was a gradual decrease in the seedling length might be due to effect of $\mathrm{NaCl}$ salt (Anbumalarmathi and Mehta, 2013). In the present study also decreased seedling length was recorded due to higher salt concentration. However the seeds primed with $\mathrm{H}_{2} \mathrm{O}_{2}$ @ $0.25 \%$ concentration recorded an increased seedling length in all the three rice varieties of salt tolerant (TNAU Rice TRY 3), salt sensitive (ADT (R) 49) and moderately salt tolerant (Co 43) at different salt concentrations. But the stability had been maintained even in sensitive variety and results were illustrated in figure $1 \mathrm{~B}$.

The seedling vigour and dry matter production showed inverse relationship with salt concentrations. Generally the salt tolerant (TNAU Rice TRY 3) and moderately salt tolerant varieties recorded maximum dry matter production and seedling vigour when

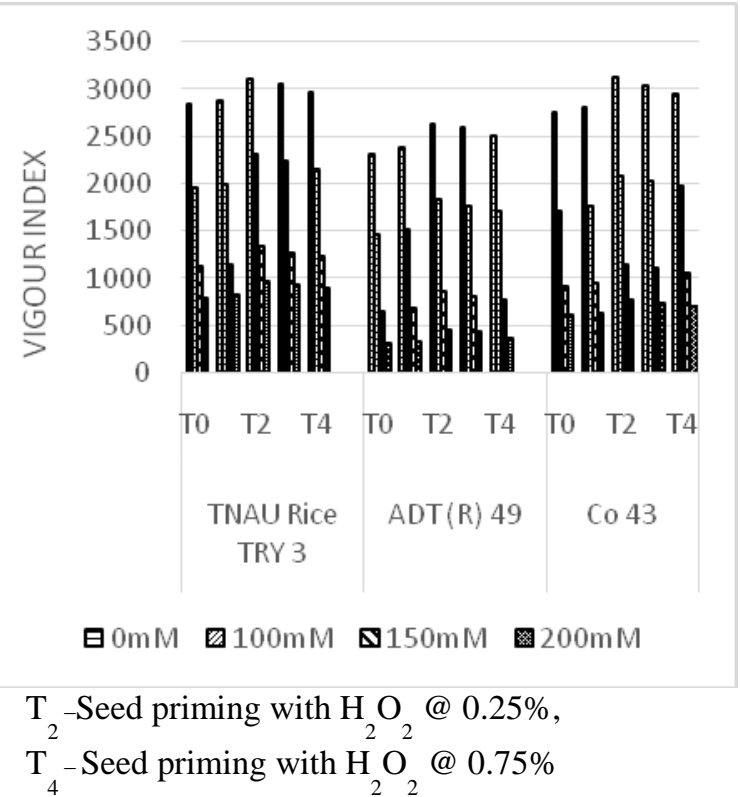

compared with salt sensitive variety and results were illustrated in figure $1 \mathrm{C}$ and $\mathrm{D}$. Similar results were observed in rice and wheat, the seedling length and dry weight were decreased with increased salt stress (Jamil and Rha, 2007).

From the present study it is clearly evident that $\mathrm{H}_{2} \mathrm{O}_{2}$ can be an important signal molecule for abiotic stress tolerance, and usuage of minimal concentration enhances the physiological attributes of the rice crop even under salt stress conditions. It also conferredly increased the tolerance level of salt tolerant (TNAU Rice TRY 3), salt sensitive (ADT (R) 49) and moderately salt tolerant (Co 43) rice varieties.

Hence seed priming with $\mathrm{H}_{2} \mathrm{O}_{2} @ 0.25 \%$ could be recommended for mitigating the effect of salt stress in rice even under higher salt concentrations.

\section{References}

Ashraf, M. and Fooland, M.R. 2005. Presowing treatment a short gun approach to improve germination under saline 
and non-saline conditions. Adv Agron., 88: 223-271.

AzevedoNeto, A.D., Prisco, J.T., Eneas-Filho, J., Medeiros, J.V.R. and Gomes-Filho, E. 2005. Hydrogen peroxide pretreatment induces stress acclimation in maize plants. J. Plant Physiol., 162: 1114-22.

Azevedo, N.A.D., Prico, J.T., Eneas, F.J., Braga, A.C.E. And Gomes, F.E. 2006. Effect of salt stress on antioxidative enzymes and lipid peroxidation in leaves and roots of salt-tolerant and saltsensitive maize genotypes. Environ. Exper. Bot., 56: 235-241.

Bakht, J., Shafi, M. and Shah, R. 2010. Effect of various priming sources on yield and yield components of maize cultivars. Pak J. Bot., 42(6): 4123-4131.

Bor, M., Ozdemir, F. and Turkan, I. 2003. The effect of salt stress onlipid peroxidation and antioxidants in leaves of sugar beet Beta vulgaris L. and wild beet Beta maritime L. Plant Sci., 164: 77-84.

Bowler, C. and Fluhr, R. 2000. The role of calcium and activated oxygens as signals for controlling cross-tolerance. Trends Plant Sci., 5: 241-6.

Foyer, C.H. and Noctor, G. 2003. Redox sensing and signal ling associated with reactive oxygen in chloroplasts, peroxisomes and mitochondria. Physiol. Plant, 119: 355-64.

Gomez, K.A. and Gomez, A.A. 1984. Statistical Procedures for Agricultural
Research, John Wiley and Sons, New York.

Hakim, M.A., Juraimi, A.S., Begum, M., Hanafi, M.M., Ismail, M.R. and Selamat, A. 2010. Effect of salt stress and germination and early seedling growth of rice (Oryza sativa L.). African J. Biotech., 9: 1911-1918.

Implay, J.A. 2003. Pathways of oxidative damage. Annu. Rev. Microbiol., 57: 395-418.

ISTA. 2011. International rules for seed testing. International Seed Testing Association, Bassersdorf, Switzerland.

Jamil, M. and Rha, E.S. 2007. Response of transgenic rice at germination and early seedling growth under salt stress. Pak. J. Biol. Sci., 10: 4303-4306.

Srinieng, K., Tanatorn, S. and Aphichart, K. 2015. Effect of salinity stress on antioxidative enzyme activities in tomato cultured In vitro. Pak. J. Bot., 47(1): 1-10.

Uchida, A., Jagendorf, A.T., Hibino, T., Takabe, T. and Takabe, T.2002. Effect of hydrogen peroxide and nitric oxide on both salt and heat stress tolerance in rice. Plant Sci., 163: 515-523.

Wahid, A., M. Perveen, S. Gelani and S.M.A. Basra, 2007. Pretreatment of seed with $\mathrm{H} 2 \mathrm{O} 2$ improves salt tolerance of wheat seedlings by alleviation of oxidative damage and expression of stress proteins. J. Plant Physiol., 164: 283294.

\section{How to cite this article:}

Hemalatha G., J. Renugadevi and Eevera T. 2017. Studies on seed priming with hydrogen peroxide for mitigating salt stress in rice. Int.J.Curr.Microbiol.App.Sci. 6(6): 691-695. doi: https://doi.org/10.20546/ijcmas.2017.606.081 